\title{
Cholangiodrainage in Roux-en-Y-settings: implantation of large-caliber stents via single balloon enteroscopy
}

Biliary tract endoscopic interventions using a push and pull enteroscope in patients with Roux-en-Y-reconstruction $[1,2]$ are limited by the width of the working channel of this type of endoscope, which allows insertion of stents up to a maximum diameter of $7 \mathrm{Fr}$.

For application of larger stents, we use the non-transendoscopic method introduced by Kautz $[3,4]$, with a modified guide instrument suitable for a single balloon enteroscope (SIF-Q-180, diameter $9.2 \mathrm{~mm}$, length $200 \mathrm{~cm}$, working channel $2.8 \mathrm{~mm}$; Olympus, Tokyo, Japan). This guide instrument offers a flexible, atraumatic tip, which features a clamping device such as a papillotome. By pulling on an inner wire, the tip is flexed down and can be anchored in a peripheral bile duct; this is done through a connectable handle at the other end of the guide instrument ( $\bullet$ Fig. 1).

After administering contrast in the biliary tract ( Fig. 2) the guide instrument is inserted into a peripheral intrahepatic bile duct.

The guide instrument can be steered by controlled tension and release of the tip using the handle under fluoroscopic visualization. After the guide instrument has reached its correct position it is locked in place by tensioning the tip ( $\bullet$ Fig. 3 ).

With the guide instrument in position the handle is disconnected and the endoscope is removed. After dilation, the stent (14 Fr) and its pusher are attached to the guide instrument ( Fig.4) and after positioning the stent under fluoroscopic guidance, the guide instrument is released and removed like a usual guide wire ( $\bullet$ Fig. $\mathbf{5}$ ).

Custom-built accessories (guide instrument, pushers, dilators) of adequate length are available (MTW-Endoskopie, Wesel, Germany).

The method described here offers the opportunity to insert large biliary stents via a Roux-en-Y anastomosis in patients in whom the papilla is only accessible by a push and pull enteroscope.

\section{Competing interests: None}

Endoscopy_UCTN_Code_TTT_1AR_2AK

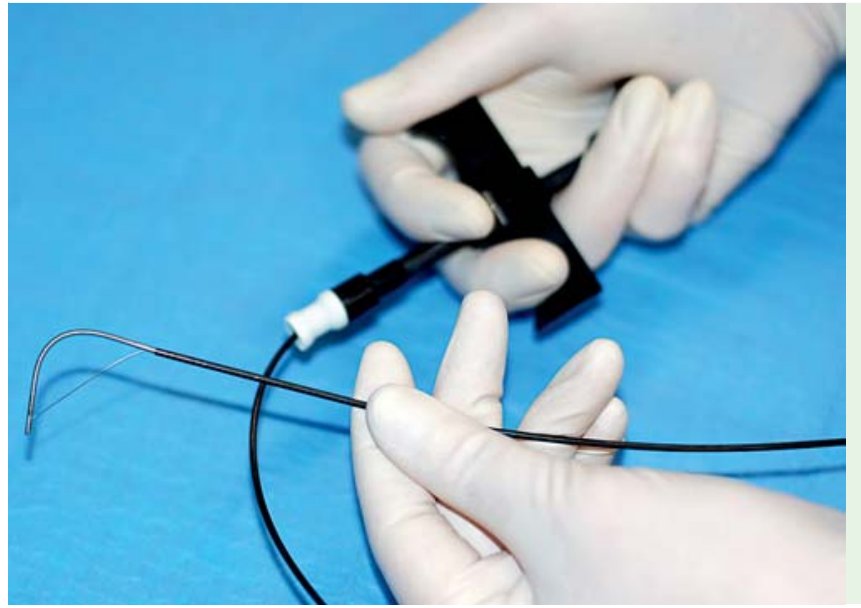

Fig. 1 Guide instrument with connectable handle in a flexed-down position.

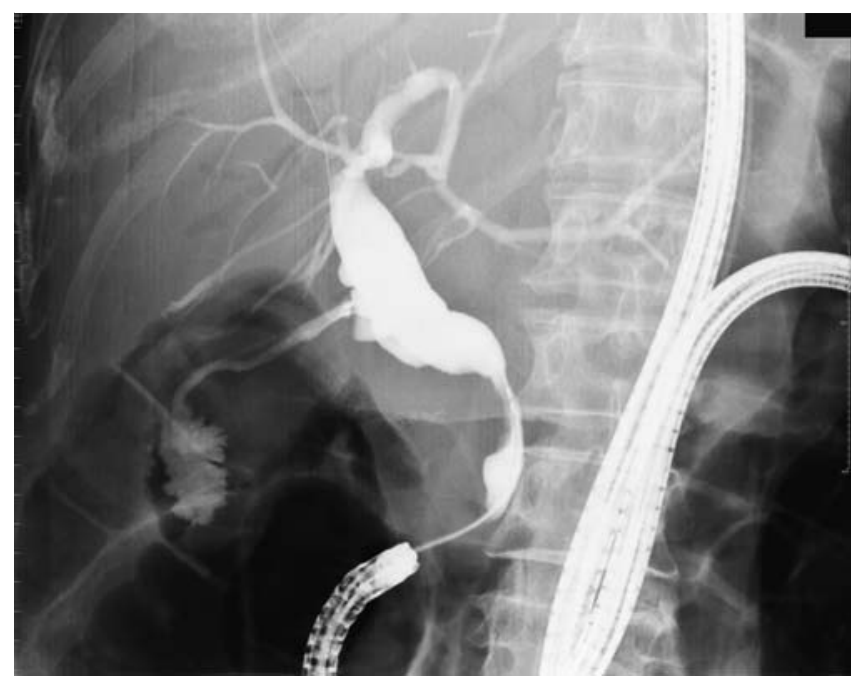

Fig. 2 Administering contrast in the biliary tract.

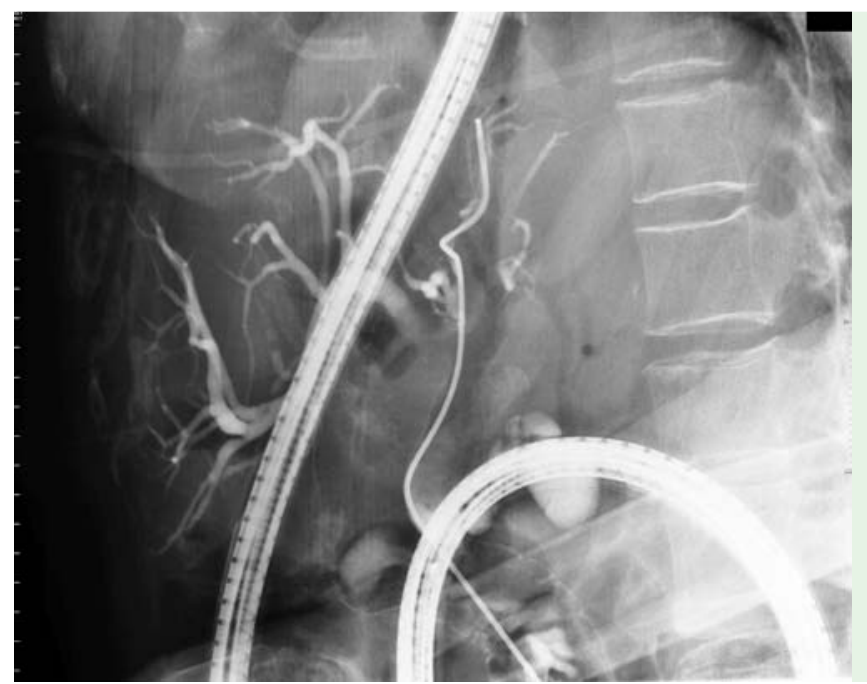

Fig. 3 The guide instrument is inserted into a peripheral bile duct and locked in place by tensioning. 


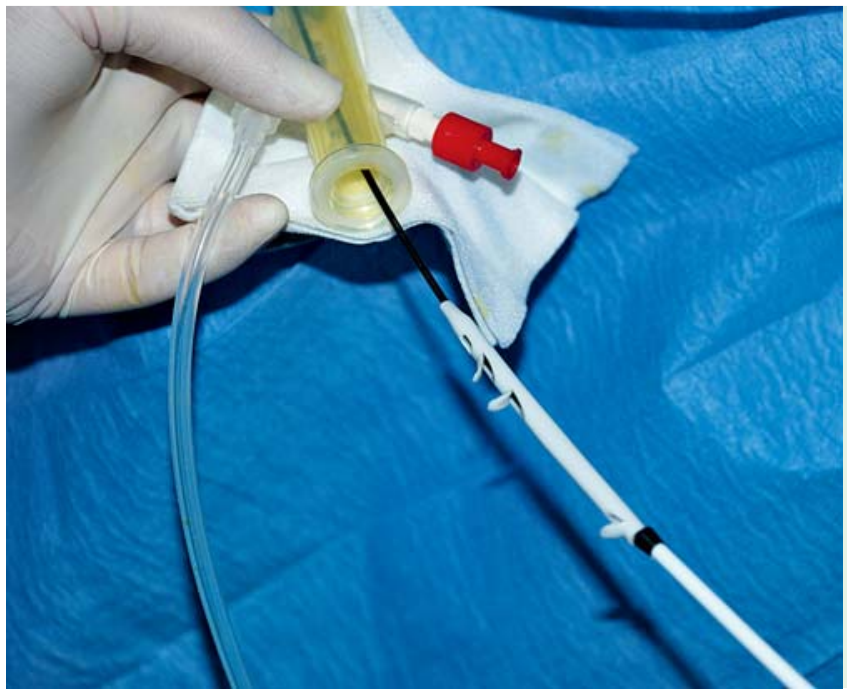

Fig. 4 Overtube and guide instrument with attached stent and pusher.

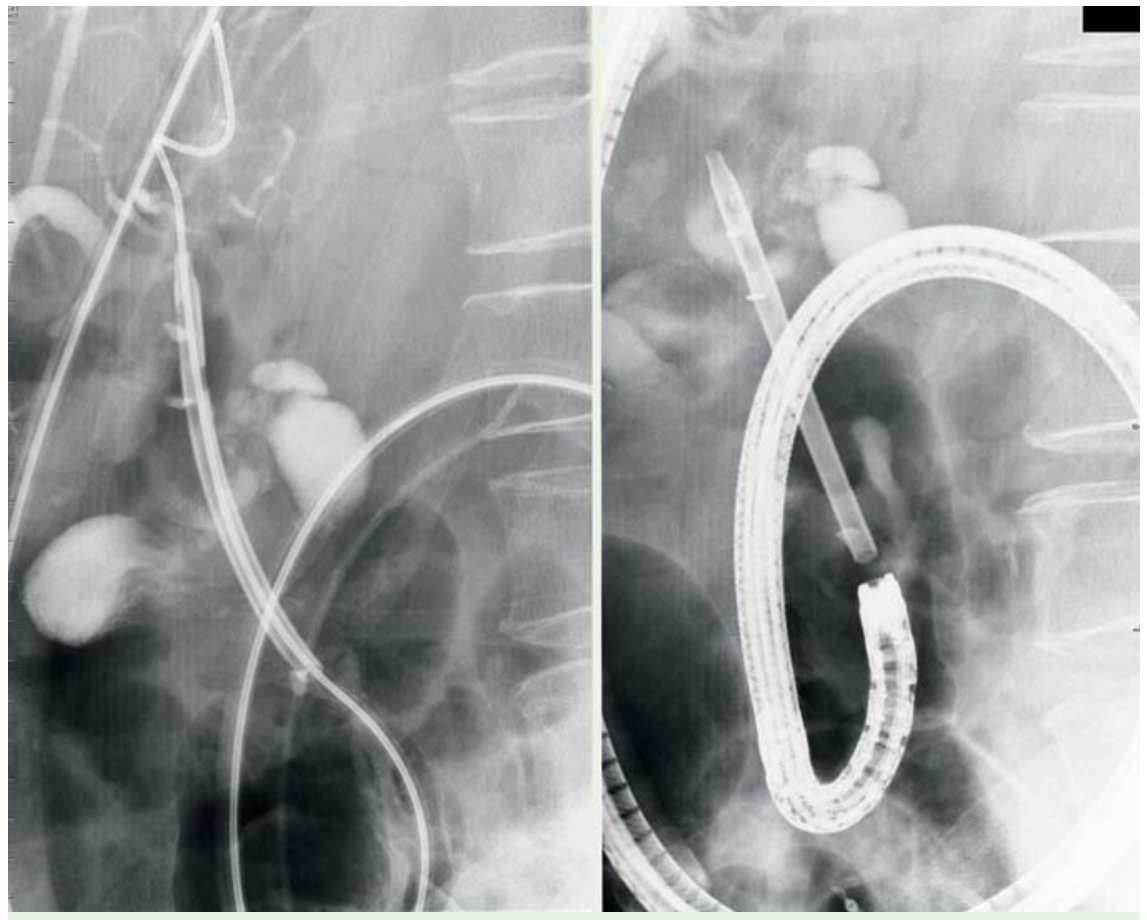

Fig. 5 Left panel: The endoscope has been removed and the overtube and guide instrument are still in position. The pusher is visible proximal to the stent and duodenum is identified by air contrast. Right panel: After removal of the guide instrument the correct position of the stent is confirmed by repeat endoscopy.

\section{Albers, U. Peitz}

Department of Gastroenterology,

Raphaelsklinik, Academic Teaching Hospital of the University of Muenster, Muenster, Germany

\section{References}

1 Aabakken L, Bretthauer M, Line PD et al. Double-balloon enteroscopy for endoscopic retrograde cholangiography in patients with Roux-en-Y anastomosis. Endoscopy 2007; 39: 1068-1071

2 Dellon ES, Kohn GP, Morgan DR et al. Endoscopic retrograde cholangiopancreatography with single-balloon enteroscopy is feasible in patients with a prior Roux-en-Y anastomosis. Dig Dis Sci 2009; 59: $1798-$ 1803

3 Kautz G. Transpapillary bile duct drainage with a large caliber endoprosthesis. Endoscopy 1983; 15 : $312-315$

4 Kautz G, Reers B, Sprakel B et al. More successful and cost effective - the non transendoscopic method of TPCD. Z Gastroenterol 1993; 31 Suppl 2: 149-153

\section{Bibliography}

DOI $10.1055 / \mathrm{s}-0029-1244228$

Endoscopy 2010; 42: E192-E193

(c) Georg Thieme Verlag KG Stuttgart · New York . ISSN 0013-726X

\section{Corresponding author \\ D. Albers}

Department of Gastroenterology

Raphaelsklinik Muenster

Loerstraße 23

48143 Muenster

Fax: +49-2515007-2467

d.albers@raphaelsklinik.de 